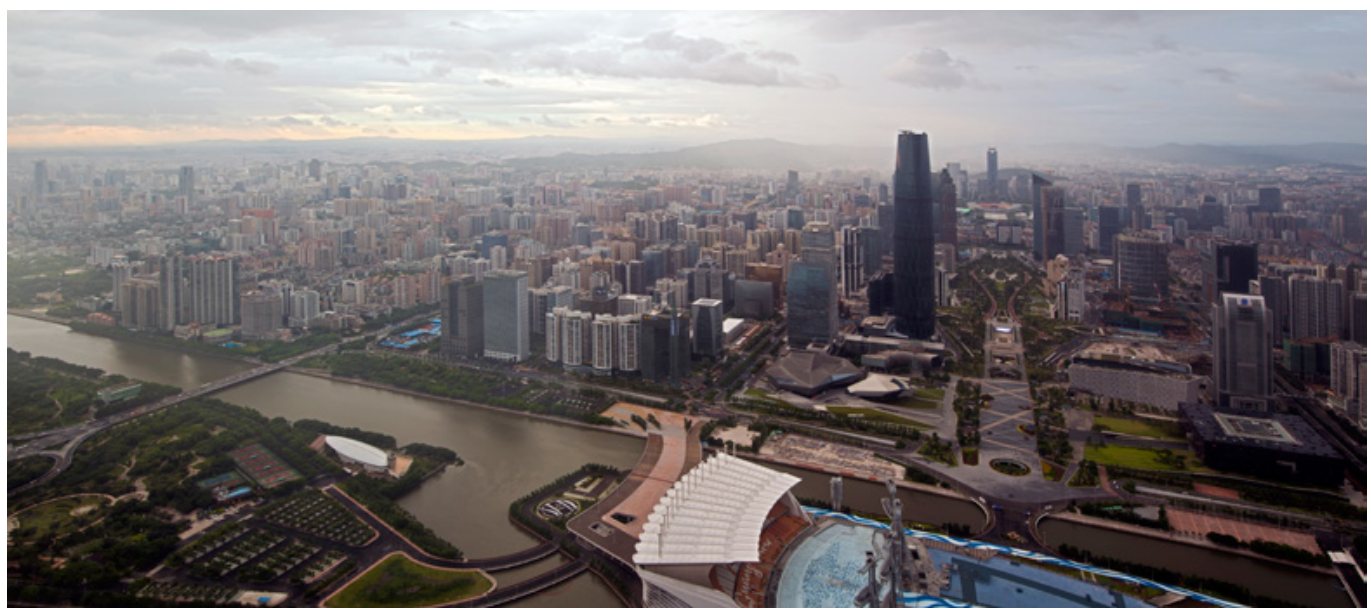

\section{Between Poetics and Utility Landscape Infrastructure in China}

Dorothy TANG

The conceptual history of landscape is mired between the dualities of poetics and utility-rooted in its origins of landscape art and the current preoccupation with alternative sustainable infrastructures. This essay unpacks the 'mutuality' of nature as a traditional cultural practice and as innovative technology in contemporary Chinese landscape architecture. The 'Sponge City' practices of promoting green infrastructure exemplify the coproduction of urban nature in scientific and cultural terms, and suggest an alternative analytical framework for urban infrastructure research in China.

Research for this project is funded by the Sin Waikin Junior Fellowship at the Hong Kong Institute of Humanities and Social Sciences.
Tianhe District, Guangzhou. PC: Wikimedia Commons. ou use a literal translation of
landscape architecture in Hong
Kong!' Colleagues from mainland China often exclaim after dutifully examining my business card. Indeed, the use of the phrase 园境建筑 (yuan jing jianzhu) in Hong Kong betrays its British origins and North American influence. Yuan can be translated into park or garden, jing is the environment, and lastly jianzhu, or architecture, references the nineteenth-century term Frederick Law Olmsted first used to signal landscape architecture as a modern profession in America. Landscape architects in Hong Kong were first commissioned to work on new town development in the 1970s based on Garden City principles. The word choices for 'landscape' reflect their modernist optimism in the role of public urban landscapes and their desire to be recognised for their contributions to Hong Kong's urban development (Chan 2015). In mainland China, the official term for the 
discipline is 风景园林 (fengjing yuanlin)translated as 'scenery' and 'gardens', while in Taiwan 景观设计 (jingguan sheji) can be understood as 'the design of views'. In contrast to the Hong Kong landscape architecture community's aspirations for recognition as a modern profession operating on the international stage, other Chinese translations of 'landscape' reclaim the cultural legacies of Chinese gardens and Chinese landscape paintings (山水画). Not only do these instances illustrate how the concept of landscape resists simplistic translations in China, but also suggest that this fluidity provides an analytical lens for better understanding the transformation of landscapes in Chinese cities.

The etymology of the word 'landscape' in the English language shares a pictorial origin with its Chinese counterparts. Early uses of the word refer to seventeenth-century Dutch paintings, and there exists a rich discourse in cultural geography of how the image mediates the cultural production of landscapes (Mitchell 2002; Jackson 1997; Cosgrove 1998). The poetics of Chinese paintings and literature are often cited as the origins for the symbolic expression of Chinese gardens, and while recent scholarship argues that this static pictorial view is insufficient, the role of landscape paintings is still central to understanding its cultural production and spatial experiences (Fung 2016). Building on these theories of 'reciprocity between ways of seeing and ways of doing', US-based landscape architect James Corner (1999b, 9) argues that even the technical drawings landscape architects produce are speculative and projective, and reveal underlying cultural values and ideologies. He then proposes that the work of mapping and drawing the physical environment should be an art form that not only critiques the present but actively shapes political and social futures (1999a, 1999c).

On the other hand, landscape architecture is considered a rational and scientific practice. Corner describes contemporary practice as steeped in 'a deep concern with landscape's conceptual scope, with its capacity to theorize sites, territories, ecosystems, networks, and infrastructure, and to organize large urban fields' $(2006,23)$ as a response to global environmental awareness. Chinese landscape architect Yu Kongjian describes his approach as using 'ecological planning methodologies' to rationalise cities on 'a solid ecological basis' (2016b, 165-66) in order to address the environmental crisis of urban China due to unchecked growth. Interestingly, Yu's ecological discourse finds its roots in traditional fengshui (风水), Chinese geomancy, as its spiritual and cultural source, but locates its technical expression in the work of ecological planner Ian McHarg's seminal book Design with Nature (Yu 2011, 154-55). Corner and $\mathrm{Yu}$ are arguably two of the most prominent landscape architects and thinkers in their respective national spheres, and we observe striking similarities in their quests to reconcile landscape as both a culturally specific practice and a site of ecological rationality. If we dig deeper, we find that the national distinctions are much more complicated: Corner is British but based in the United States and has acquired significant commissions in Chinese cities, while $\mathrm{Yu}$ is Harvard-educated and active in professional circles in the United States. As landscape architectural practice and education is increasingly globalised, isolating origins of cultural practices or analysing the directionality of knowledge transmission also seems to be a futile endeavour.

In an insightful essay titled 'Mutuality and Cultures of Landscape Architecture', architectural historian Stanislaus Fung traces instances where practices of Western landscape architecture find parallels in Chinese gardens (1999). However, he reminds us that the concepts of 'mutuality'-defined as forms of interdependence and coproduction-found in Chinese landscapes are a critical distinction from traditions of Western dualistic thinking. For example, classic Chinese garden spatial techniques such as interdependence (yin) [因], borrowing (jie) [借], suitability ( $t i$ ) [体], and appropriateness $(y i)$ [宜] follow a nondualistic logic' $(1999,147)$, whereas Western landscape 
traditions emphasise dualities that act to exclude (e.g. the culture/nature binary). He also proposes that the current form of landscape architecture in China could be analysed through the lens of cultural mutuality-the product of long-standing mutual exchanges between China and Western institutions, rather than postcolonial critiques of uneven power. This essay borrows Fung's formulation of mutuality to explore the relationships between landscape, infrastructure, and nature, in order to contextualise the widespread adoption of green infrastructure in Chinese cities. I then use the work and writings of Yu Kongjian-a major advocate for the Chinese 'Sponge Cities' green infrastructure policy-to unpack discourses of China's ecological urbanisation, before concluding with observations about 'spatial practices' (de Certeau 2002) of implementation in the Pearl River Delta.

\section{From Landscape to Infrastructure}

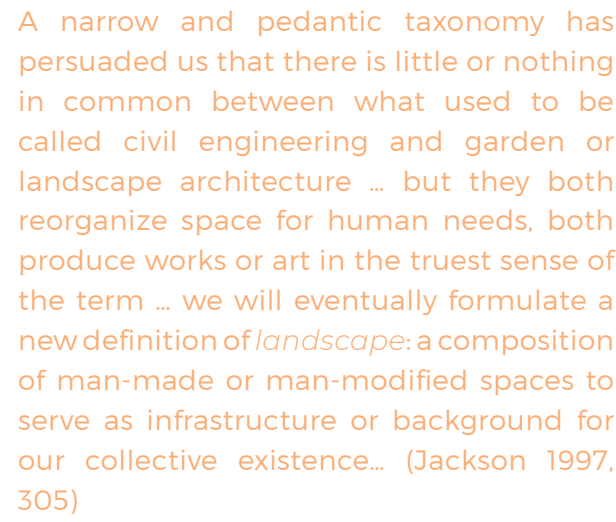

Originallywritten in 1984, culturalgeographer J. B. Jackson's essay The Word Itself argues that landscape is a 'concrete, three-dimensional, shared reality' rather than a metaphor to describe the general state of all affairs (1997, 304). Jackson's call to reconceive the ontology of landscape as infrastructure foreshadows anthropologist Brian Larkin oft-quoted article
'The Politics and Poetics of Infrastructure', which argues that 'infrastructures are matter that enable the movement of other matter. Their peculiar ontology lies in the facts that they are things and also the relation between things' (2013, 329). Despite the parallels of landscape or infrastructure as underlying systems that sustain human existence, the shifting definitions of nature over time and across cultures (Cronon 1995; Nye 1999) impact their utility respectively. By comparing the co-evolution of nature-infrastructure and nature-landscape, two diverging genealogies of 'landscape infrastructure' materialise: the first is the notion that landscapes are in service of infrastructure, and second is that landscape is infrastructure.

\section{Landscape in Service of Infrastructure}

Modernist narratives of infrastructure are often tales of control over natural forces: streams are channelised, land is reclaimed, disease is eliminated, and rivers are dammed (Carse 2017; Graham and Marvin 2001; Kaika and Swyngedouw 2000). Nature in this view is an environment to be stabilised or a resource to be extracted, and infrastructure is the medium in which these human desires are satisfied (Edwards 2003). The development of the iconic Tennessee Valley Authority (TVA) project in the 1930s is an apt example of how the development of large technological systems eventually relied on the management of landscapes (Hughes 1987). Shortly after completion, it became clear that soil erosion due to poor farming practices in the TVA watershed was causing sedimentation problems, and plans were quickly formed to educate farmers about landscape management and the provision of chemical fertilisers to increase vegetative cover within the watershed (Wolff 2007). Similarly, huge afforestation projects within the watersheds of major reservoirs were carried out in Hong Kong by 
the British colonial government to ensure water security for the colony (Peckham 2015). The management of natural landscapes was subsumed as a critical system component in large-scale infrastructural systems of extraction (Carse 2012).

With increasing development pressures and the rise of environmental consciousness after World War II, landscape architect Ian McHarg pioneered an ecological planning paradigm outlined in his 1969 book Design with Nature. Taking an apocalyptic tone of impending environmental disaster, McHarg offered a methodology that required an extensive inventory of natural systems to determine the 'suitability' of a landscape for urban development. Working with natural systems by planning around them, in McHarg's view, utilised the full potential of limited land for urbanisation and guaranteed a sustainable future (McHarg 1992). While not explicitly extractive, the rationales of sustainability are found in optimisation and replenishment, and its tools include the scientific management of natural resources-e.g. recycling-or the technological enhancement of nature-e.g. green roofs. The logical culmination of this trajectory is the quantification, monetisation, and trading of ecological benefits, frequently conceptualised as 'eco-system services' or 'natural capital'. In short, the modernist infrastructural impulse of rationalising nature to serve human desires has evolved into the mandate for the regulation of green spaces, renewable energy, or water recycling as a means to justify future urban development.

\section{Landscape Is Infrastructure}

The pictorial origins of 'landscape' are entangled with the evolving concept of 'nature'. The eighteenth-century English landscape garden was composed with picturesque principles that mediated the extremes of nature as sublime and the artificial as beautiful. The work of Frederick Law Olmsted in the second half of the nineteenth century introduced a new function of nature-as civic infrastructureinto the practice of landscape architecture. If New York's Central Park exemplifies nature as a social good in the industrialised city, then Boston's Back Bay Fens utilises nature as sewage infrastructure in the rapidly-developing city. Despite the naturalistic appearance of Olmsted's landscapes, nature was no longer understood only as an aesthetic object, but as providing a vital service to the public health of urban residents. Some have argued that the naturalistic aesthetic of Olmsted's landscapes masked the legibility of the ecological performance of his designs and were later overlooked or destroyed (Spirn 1995). Disputes over the appropriate aesthetics of ecological landscapes continues today (Nassauer 1995; Meyer 2008), but perhaps what these debates reveal is the refusal of essentialising nature to a science, a resource, or a view.

The bundling of cultural practices and ecological processes in the landscape has recently found a new voice in 'landscape urbanism'-a claim that landscape systems should be the primary actor in shaping the city (Waldheim 2006). Responding to the rise of post-industrial cities and the decline in infrastructural investment in the United States, landscape urbanists expanded their scope of interest to under-utilised spaces as a by-product of urbanisation, contaminated sites, modified natural systems, or refuse and waste, to argue for an ethical return to 'landscape infrastructures' (Berger 2006; Kirkwood 2001; Corner 2005). By pitting the 'grey' infrastructures within the domain of engineering against 'green' or 'ecological' infrastructures of the landscape, the rationale shifts from privileging the technical efficiency of single-function infrastructure to recognising that landscapes have the potential to address economic, social, and environmental concerns, albeit over greater time scales or spaces (Bélanger 2009). More importantly, landscape urbanism borrows heavily from recent developments in systems ecology that 
no longer understands nature as a closed and stable system but rather as one that is dynamic and open-ended-one that defies management or control (Lister 2007). This design approach has gained much traction in recent years with the slow but volatile threat of climate change, and the discussion has turned from infrastructure as protection to infrastructure creating a platform for resilience (Bélanger 2017).

\section{Sponge Cities: Landscape and Infrastructure in China}

How does this history of landscape infrastructure in North America relate to a register of Chinese infrastructure? The speed and scale of China's 'infrastructure boom' has befuddled Western critics-from the extent of subway lines in Shanghai to the Three
Gorges Dam, especially when in the West highmodernist forms of infrastructure and their post-war ideologies are heavily criticised. In contrast to the crumbling and underfunded infrastructure of North America, Western media has described China's boom in terms of corruption (Buckley 2017) or 'risky technical solutions' (Wines 2011), assuming accelerated obsolescence in China. However, in the wake of the Hurricane Harvey that hit the American coastal city of Houston in 2017, an article in The Guardian featured five urban visions of what 'entirely flood-proof cities would look like'-one of which was China's Sponge City programme (Knight 2017). As China aspires to take on global leadership regarding climate change, Western media outlets from $C N N$ to Scientific American have made Chinese sponge cities a legitimate poster child (Biswas and Hartley 2017; Gies 2018).

Launched in late 2013 after devastating floods in Beijing that killed 79 people, President Xi Jinping announced an ambitious programme to convert all Chinese cities into

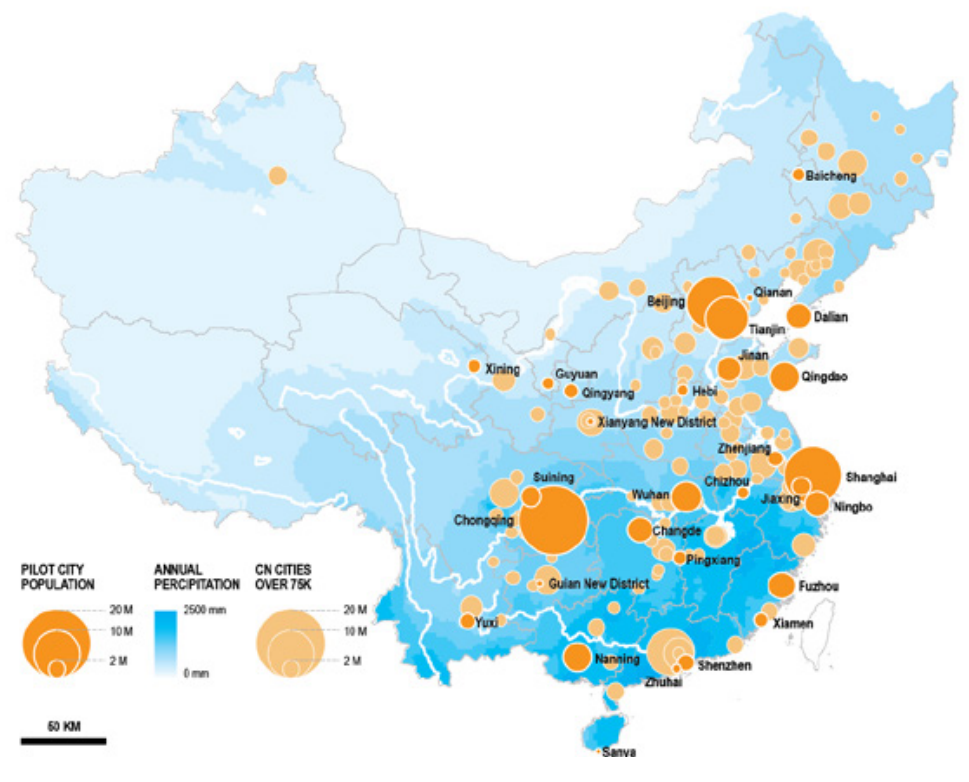

(Figure 1) 30 pilot cities throughout China were selected within two years of President Xi's announcement of the Sponge City programme. PC: Dorothy Tang. 
'sponge cities' by 2030. The programme aims to lessen urban floods by using dispersed landscapes throughout the city to absorb rain like a sponge, rather than through the more immediate and centralised pipe drainage systems. The national scale and rapid rollout of the programme sets it apart from other ecocity experiments in China's recent past. Within a year of Xi's announcement, Sponge City technical guidelines were issued (MOHURD 2014), and by early 201630 pilot cities had begun work on converting their stormwater drainage infrastructure. Yet, this process is far from uniform and smooth. The technologies adopted by the technical handbook reveal its roots in sustainability practices developed since the 1980s in the West and Japan, including a range of strategies such as green roofs, storage tanks, porous pavement, infiltration strips, and treatment wetlands (Geiger 2015). These strategies are most effective when implemented in new development projects, but are more often piecemeal conversions due to constraints in the existing urban fabric. In addition, while these technologies are not necessarily new, the massive scale of implementation in a compressed timeframe meant that there was widespread shortage of expertise in both local governments and design institutes. Out of this chaos emerged two main camps of expertise, the first is led by a group of environmental engineers who were instrumental in drafting the Sponge City technical handbook; and another revolving around landscape architect Yu Kongjian.

In 2018, I interviewed $\mathrm{Yu}$ about his role in shaping the Sponge Cities initiative and its origins. He suggested that Xi was inspired by his landscape designs that 'absorbed water like a sponge' to prevent flooding, and he was adamant that its conceptual origins were not Western. 'Sponge cities are very Chinese,' he remarked, 'first, the concept of sponge cities is rooted in Chinese philosophies of transformations, from large to small, from centralised to distributed, from hard to soft, and from grey to green. Second, it responds to the natural environment of China and is a return to our heritage of an agricultural civilisation ... .' However, Yu cautioned, the traditional cultures that inform the Sponge City are not the same as conventional elite Chinese knowledge, such as the legendary heroic flood control infrastructures of the Yellow River 4000 years ago built by Yu the Great. Instead, sponge cities are inspired by the everyday agricultural practices of peasants. To Yu, generic implementation of imported stormwater management technologies did not address the urgent demands of the Sponge City programme. Rather the Sponge City should bridge the scientific approach of largescale watershed management and the cultural practice of landscape architecture that respects its 'peasant' origins (Yu 2016).

The concept of mutuality is useful here in unpacking Yu's claims. Yu's doctoral work at Harvard's Graduate School of Design was supervised by Carl Steinitz, who specialised in the use of computer analytics for planning, and landscape ecologist Richard T. T. Forman (Saunders 2012). Upon return to China, he founded the Graduate School of Landscape Architecture at Peking University, which is known to be a research-focussed and scientifically-oriented professional programme. It seems that Yu's experiences and rhetoric echo the modernist avant-garde embrace of Western rationality and faith in the scientific method, and yet rather than rejecting history completely he is selective in whose traditions are valid. $\mathrm{He}$ is critical of the importation of foreign expertise to address Chinese problems, yet relies on foreign validation to maintain professional legitimacy. For Yu, these are not dualistic or contradictory terms, but rather co-constituted and cohesive. Contemporary Chinese nature is best managed with the guiding principles of traditional agricultural practices in conjunction with the scientific quantification of ecological services. Thus, landscape infrastructure-as expressed in the Sponge City programme-has the capacity to embody both the rationales of nature as a commodity and as a cultural practice. 


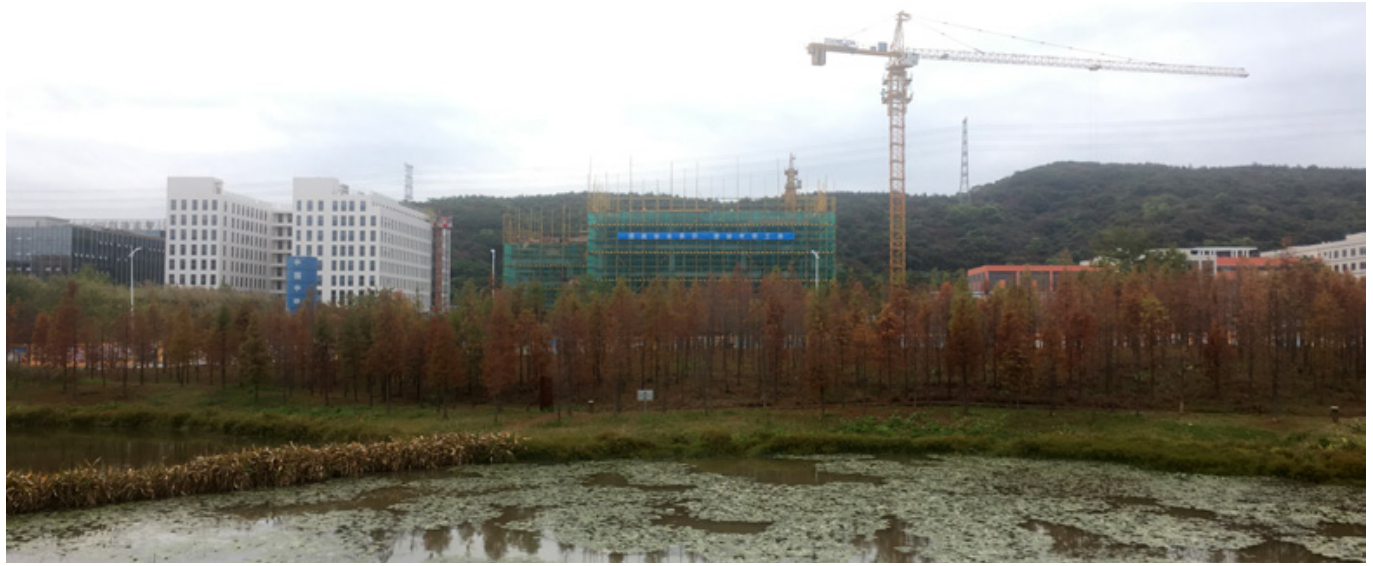

\section{Sponge Cities as a Spatial Practice}

After interviewing Yu Kongjian, I went to visit a newly completed Sponge City project designed by his firm, Turenscape. Daguan Wetland Park (Figure 2) is a component of Tianhe Intelligent City, one of Guangzhou's flagship development projects and forays into the IT sector. Yu's vision for the Sponge City was intended to be realised through comprehensive ecological planning at the watershed scale and sponge projects were to be implemented strategically to maximise infiltration and treatment of stormwater. However, when I overlaid administrative boundaries with watershed boundaries on a map (Figure 3), I found that the wetland park does not receive stormwater from its surrounding development and only absorbs excess rainwater within its boundaries. Despite the lushly planted wetland-populated with native plants selected to filter urban pollutants-the utopian ideal of a landscape for a liberated peasant was diminished with the jarring noise of ongoing construction and a forest of cranes just beyond the wetland, erecting glazed curtain-wall office towers for a not-yet existent IT sector. Furthermore, in my conversations with the project manager at Turenscape, densely-populated urban
(Figure 2) Construction of office building complexes adjacent to Daguan Wetland Park in Guangzhou designed by Turenscape. PC: Dorothy Tang, 10 January 2018.

villages with inadequate drainage and sewage infrastructure within the watershed posed great challenges to systematically satisfying stormwater targets set for the district.

In a canonical text distinguishing the theoretical gaze of the planner and designer from the daily experiences of those walking in the city, Michel de Certeau argues that the 'spatial practices' of the everyday produce 'lived spaces' that cannot be understood through the abstract practices of the planner (de Certeau 2002). However, in China the binary structure of the theoretical gaze in contrast to everyday spatial practices needs to be expanded as well. In the case of Daguan Wetland Park, the theoretical extent of landscape infrastructure is violated by the everyday practices of various levels of the state, real estate developers, planning and design consultants, urban villagers, and IT workers. While proponents of 'landscape as infrastructure' have embraced uncertain futures and dynamic ecological systems, this concept still heavily relies on the theoretical gaze of the planner, and has yet to fulfil J. B. Jackson's notion of landscape as an infrastructure for our collective existence. 


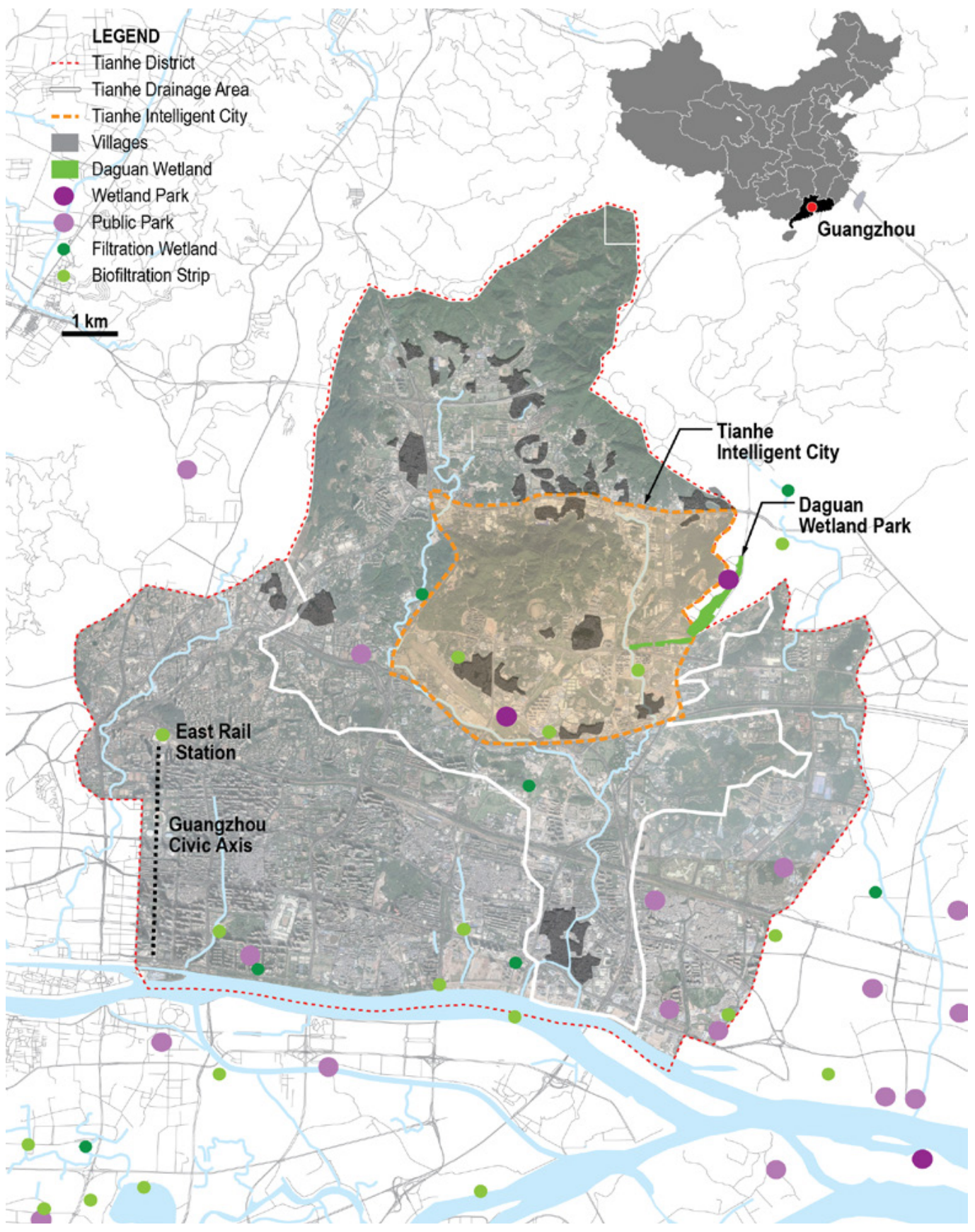

(Figure 3) Spatial relationship between the Tianhe Intelligent City, Daguan Wetland Park, Tianhe

Drainage Area, and Tianhe Administrative district in Guangzhou. PC: Dorothy Tang. 